\title{
Megaloblastic Madness: A Reversible Neuropsychiatric Condition
}

\author{
Indar Kumar Sharawat ${ }^{1} \cdot$ Prateek Kumar Panda $^{1}$ (B)
}

Received: 25 May 2020 / Accepted: 10 June 2020 / Published online: 16 June 2020

(C) Dr. K C Chaudhuri Foundation 2020

To the Editor: A 13-y-old girl, on an exclusively vegetarian diet, was brought with complaints of progressive pallor, easy fatigability, and breathlessness on exertion for the last one month and poor sensorium for two days. Apart from severe pallor and mild hepatosplenomegaly she also had delirium, not recognizing caregivers, not indicating basic needs, visual hallucinations, irrelevant talk, and intermittent aggressive behavior. There were no signs of congestive cardiac failure or pulmonary edema. There was no meningeal sign or focal deficit, but she had ankle hyporeflexia.

Investigations showed anemia (Hemoglobin $-3 \mathrm{~g} / \mathrm{dl}$ ), leucopenia (leucocyte count $-1200 / \mu \mathrm{L}$ ), and thrombocytopenia (platelets $-54,000 / \mu \mathrm{L})$. Her mean corpuscular volume $(\mathrm{MCV}$; $105 \mathrm{pg})$, serum bilirubin $(1.8 \mathrm{mg} / \mathrm{dl})$ and lactate dehydrogenase (LDH; $748 \mathrm{IU} / \mathrm{L}$ ) levels were elevated. Peripheral smear showed macroovalocytes. Serum B12 level was low $(112 \mathrm{ng} / \mathrm{ml})$. Gadolinium-enhanced MRI of brain and spine, CSF examination, the workup for the neurotropic virus, autoimmune encephalitis, and systemic sepsis were negative. She was started on injectable vitamin B12 $1 \mathrm{mg}$ daily for a week apart from packed red blood cells (PRBC) transfusion and showed gradual improvement in sensorium and neuropsychiatric features. The child was discharged on oral vitamin B12 supplementation and follow up at 1 mo revealed normal neuropsychiatric examination.

Clinical manifestations of vitamin B12 deficiency can be broadly divided into hematological and neurological symptoms and both have different pathogenetic mechanisms [1]. Subacute combined degeneration of spinal cord, peripheral neuropathy (paresthesia, gait abnormality), and neuropsychiatric features like delusion, hallucination, irritability, depression, mania, emotional lability, bipolar disorder, paranoia and memory disturbance are the usual neurological symptoms associated with vitamin B12 deficiency [2, 3]. Most patients usually have isolated

Prateek Kumar Panda

drprateekpanda@gmail.com

1 Pediatric Neurology Division, Department of Pediatrics, All India Institute of Medical Sciences, Rishikesh, Uttarakhand, India neurological symptoms and the degree of megaloblastic anemia usually appears to inversely correlate with the severity of neuropsychiatric symptoms [3]. Accumulation of methylmalonic acid and homocysteine due to inadequate functioning of L-methyl malonyl-coenzyme A mutase and methionine synthetase are responsible for neurological dysfunction [3]. The young age at onset of neuropsychiatric features and co-existence of severe hematological and neurological symptoms (megaloblastic madness) in our case is atypical, but clinicians need to be aware of this entity, as timely vitamin B12 therapy can reverse these symptoms completely $[4,5]$. Interestingly, in patients with neurological symptoms, lower hematocrit level is a predictor of severity of symptoms after adjusting for confounders like age, sex, $\mathrm{MCV}$, disease duration, and serum vitamin B12 level. At the same time, the presence of anemia predicts a more prompt and better neurological response and more favorable long term recovery, which might be the reason behind rapid reversal of symptoms with B12 therapy in our patient [3].

\section{Compliance with Ethical Standards}

Conflict of Interest None.

\section{References}

1. Dawman L, Sharawat IK, Vinay K. Blue nails: window to micronutrient deficiency. BMJ Case Rep. 2018. https://doi.org/10.1136/bcr2018-224258.

2. Issac TG, Soundarya S, Christopher R, Chandra SR. Vitamin B12 deficiency: an important reversible co-morbidity in neuropsychiatric manifestations. Indian J Psychol Med. 2015;37:26-9.

3. Rannelli L, Watterson R, Pandya R, Leung AA. Vitamin B12 deficiency with combined hematological and neuropsychiatric derangements: a case report. J Med Case Rep. 2014;8:277.

4. Tufan AE, Bilici R, Usta G, Erdoğan A. Mood disorder with mixed, psychotic features due to vitamin B12 deficiency in an adolescent: case report. Child Adolesc Psychiatry Ment Health. 2012;6:25.

5. Newbold HL. Vitamin B-12, megaloblastic madness, and the founding of Duke University. Med Hypotheses. 1988;27:231-40.

Publisher's Note Springer Nature remains neutral with regard to jurisdictional claims in published maps and institutional affiliations. 